\title{
2'-Spirocyclopropyl-carbocyclic Nucleoside as a Novel Scaffold for Potent Anti-HCV Agents
}

\author{
Hua Li, Jin Cheol Yoo, and Joon Hee Hong* \\ BK21- Project Team, College of Pharmacy, Chosun University, Kwangju 501-759, Korea \\ *E-mail:hongjh@chosun.ac.kr \\ Received January 5, 2011, Accepted January 28, 2011
}

\begin{abstract}
The discovery of 2'-spirocyclopropyl-ribocytidine ( $J$. Med. Chem. 2010, 53, 8150-8160) as a potent inhibitor of RNA synthesis by NS5B $\left(\mathrm{IC}_{50}=7.3 \mu \mathrm{M}\right)$, the RNA polymerase encoded by hepatitis C Virus (HCV), has led to the synthesis and biological evaluation of several carbocyclic versions of 2'-spiropropyl-nucleosides. The cyclopentenol intermediate 7 was successfully constructed via ring-closing metathesis (RCM) from divinyl 6. Spirocyclopropanation of enone $\mathbf{8}$ was effected by using (2-chloroethyl)-dimethylsulfonium iodide and potassium tert-butoxide to form the desired intermediate 9. The synthesized nucleoside analogues 21-24 were assayed for their ability to inhibit HCV RNA replication in a subgenomic replicon Huh7 cell line. Among them, the cytosine nucleoside analogue 22 exhibited significant anti-HCV activity $\left(\mathrm{EC}_{50}=18.2 \mu \mathrm{M}\right)$.
\end{abstract}

Key Words : Anti-HCV agent, Ring-closing metathesis, 2'-Spirocarbocyclic nucleoside

\section{Introduction}

Hepatitis $\mathrm{C}$ virus (HCV) infection is a leading cause of chronic hepatitis, liver cirrhosis and hepatoma carcinoma. ${ }^{1}$ However, there is no effective chemotherapy for the treatment of $\mathrm{HCV}$ infection except immunotherapy using ribavirin in combination with interferon- $\alpha$, which leads to a sustained virological response in only about half of the patients treated. ${ }^{2}$

To date, despite extensive exploration of many novel scaffolds, ${ }^{3}$ including carbocyclic derivatives, ${ }^{4}$ only two different classes of potent HCV nucleosides have progressed. The first such class of HCV nucleoside inhibitors (NIs) encompasses 2'-modified ribonucleoside derivatives, with 2 '- $\beta-C$-methyl analogues being particularly important. Among these derivatives, 2'-methylcytidine ${ }^{5} 1$ and 2'-methyl-2'-fluoro-

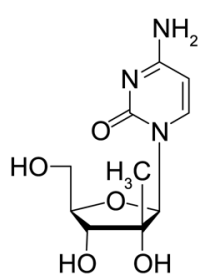

2'-Methylcytidine (1)

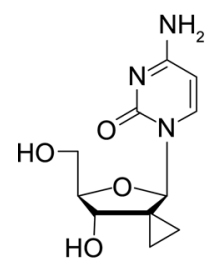

2'-Spirocyclopropyl cytidine (3)

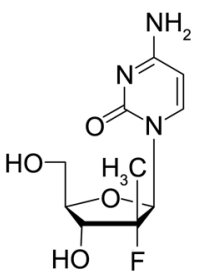

2'-Methyl-2'-fluorocytidine (2)
Figure 1. Structures of potent anti-HCV agents. cytidine $^{6} 2$ led to the most promising HCV NIs (Figure 1). Through further modification of these derivatives, 2'-deoxy-2'spirocyclopropylcytidine $^{7} \mathbf{3}$ was discovered as a new member of the class of 2'-modified nucleoside derivatives that have $\mathrm{HCV}$ inhibiting properties. Compound $\mathbf{3}$ is a novel potent $\left(\mathrm{EC}_{50}=7.3 \mathrm{mM}\right)$ and selective $\left(\mathrm{CC}_{50}>98.4 \mu \mathrm{M}\right)$ inhibitor of the HCV NS5B RNA-dependent RNA polymerase, a clinically validated target for HCV treatment.

The 4'-modified ribonucleoside derivatives are the second distinct structural class of HCV NIs. Various substituents at the 4'-position of the sugar are accommodated by NS5B polymerase.

Modeling studies demonstrated the presence of a narrow, relatively hydrophobic 4'-pocket that can accommodate these substitutions, contributing to the observed enhancement in potency. $^{8}$ For example, 4 -azidocytidine ${ }^{9} 4$ showed excellent anti-HCV activity in the genotype $1 \mathrm{~b}$ subgenomic replicon system.

Natural as well as synthetic carbocyclic nucleosides ${ }^{10}$ are well known for their interesting biological activities, including antitumor and antiviral activities against a wide variety of RNA and DNA viruses. Carbocyclic nucleosides are chemically more stable and are subject to the action of the enzymes that cleave the glycosyl linkage in conventional nucleosides.

\section{Result and Discussion}

On the basis of these findings that 2'- or 4'-modified ribonucleoside derivatives exhibited excellent anti-HCV activities, we have synthesized novel classes of nucleosides comprising 4'-methyl-2'-spirocyclopropyl carbocyclic nucleoside analogues. The target compounds were prepared as shown in Scheme 1 from the key starting material 5, which was readily synthesized according to our previous published 


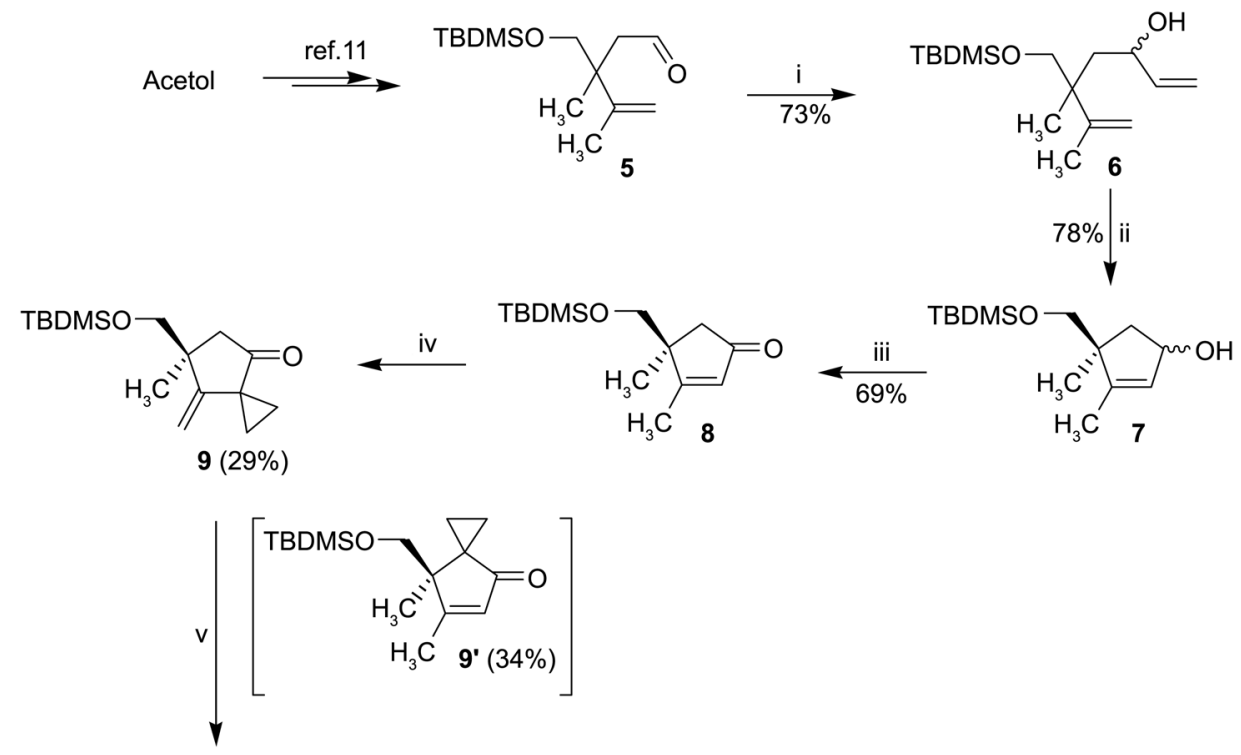

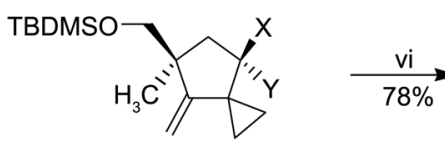

10a: $\mathrm{X}=\mathrm{H}, \mathrm{Y}=\mathrm{OH}(43 \%)$

10b: $X=\mathrm{OH}, Y=\mathrm{H}(41 \%)$
TBDMSO

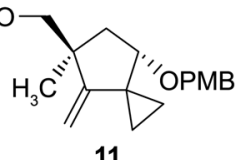

11

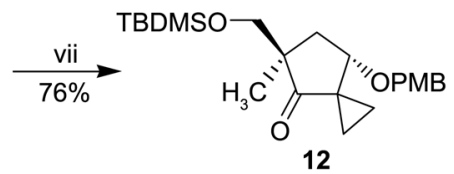

12

Reagents: i) vinylMgBr, $-20^{\circ} \mathrm{C}$, THF; ii) Grubbs catalyst (II), benzene; iii) $\mathrm{MnO}_{2}$ $\mathrm{CCl}_{4}$; iv) $\mathrm{ClCH}_{2} \mathrm{CH}_{2} \mathrm{SMe}_{2}$, KI, $t$-BuOK, $t$-BuOH; v) $\mathrm{LiAlH}_{4}$, ether; vi) PMBCl, $\mathrm{NaH}$, DMF; vii) $\mathrm{O}_{3}$, DMS, $\mathrm{CH}_{2} \mathrm{Cl}_{2}$

Scheme 1. Synthesis of spirocyclopropyl cyclopentanone intermediate.

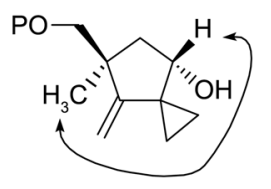

$10 \mathrm{a}(0.27 \%)$

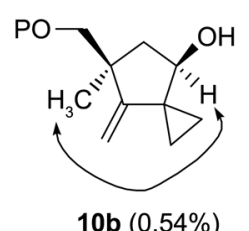

$10 \mathrm{~b}(0.54 \%)$

Figure 2. NOE differences between the proximal hydrogens of 10a and $\mathbf{1 0 b}$.

procedure. $^{11}$ The aldehyde 5 was treated with vinyl Grignard reagent to form divinyl $\mathbf{6}$. Without separation of diastereomeric mixture, divinyl $\mathbf{6}$ was subjected to ring-closing metathesis ( $\mathrm{RCM}$ ) conditions ${ }^{12}$ using $2^{\text {nd }}$ generation Grubbs catalyst to provide the cyclopentenols 7 as a diastereomeric mixture, which was then oxidized to enone derivative 8 . Spirocyclopropylation of enone $\mathbf{8}$ was effected by using (2chloroethyl)-dimethylsulfonium iodide ${ }^{13}$ and potassium tertbutoxide to form two isomers 9 (29\%) and 9' (34\%), respectively. Reduction of ketone 9 with $\mathrm{LiAlH}_{4}$ gave two diastereomeric secondary alcohols $\mathbf{1 0 a}$ and $\mathbf{1 0 b}$. The availability of both stereoisomers in pure condition allowed for confirmation of the stereochemical configuration by NOE methods (Figure 2). As expected, NOE enhancements were found between the cis-oriented hydrogens. Upon irradiation of $\mathrm{C}_{6}-\mathrm{CH}_{3}$, a weak NOE pattern was observed at the proximal hydrogen of compound 10a $\left[C_{4}-\mathrm{H}(0.27 \%)\right]$ versus those of compound $10 \mathrm{~b}\left[C_{4}-\mathrm{H}(0.54 \%)\right]$. The

secondary hydroxyl group of 10a was protected as a temporary $p$-methoxy benzyl ether (PMB) by reaction ${ }^{14}$ with $\mathrm{PMBCl}$ and $\mathrm{NaH}$ in DMF to afford the protected olefin 11. The exomethylene of $\mathbf{1 1}$ was treated with ozone in methylene chloride at $-78{ }^{\circ} \mathrm{C}$, followed by the decomposition of the ozonide by dimethylsulfide (DMS) to give the ketone 12 .

Reaction of reduction reagent $\left(\mathrm{LiAlH}_{4}\right)$ with cyclopentanone 12 proceeded from the less hindered face of the substrate to provide a mixture of cyclopentanols 13a (59\%) and 13b (25\%) (Scheme 2). In order to unambiguously confirm the stereochemistry, NOE analysis was performed on 13a and 13b. Upon irradiation of $C_{7}-\mathrm{H}$, a strong NOE pattern was observed at the proximal hydrogen of compound 13a $\left[C_{4}-\mathrm{H}\right.$ $(0.67 \%)]$ versus those of compound 13b [ $\left.C_{4}-\mathrm{H}(0.42 \%)\right]$ (Figure 3). Hydroxyl functional group of 13a was protected with $t$-butyldimethylsilyl chloride (TBDMSCl) to give compound 14. Oxidative deprotection of the PMB ether moiety of $\mathbf{1 4}$ was effected with 2,3-dichloro-5,6-dicyano1,4-benzoquinone (DDQ) $)^{15}$ in methylene chloride with a small amount of water to give the alcohol 15, which was transformed into mesylate 16 to prepare for direct $\mathrm{S}_{N} 2$ displacement involving a series of nucleoside bases. ${ }^{16}$ The protected spirocarbanucleosides 17-20 were obtained with modest efficiency by direct condensation of $\mathbf{1 6}$ with sodium salts of adenine, cytosine, uracil and thymine. Although a small quantity of the $N^{3}$-isomer (less than $6 \%$ ) of the adenine base was present, they were readily differentiated 


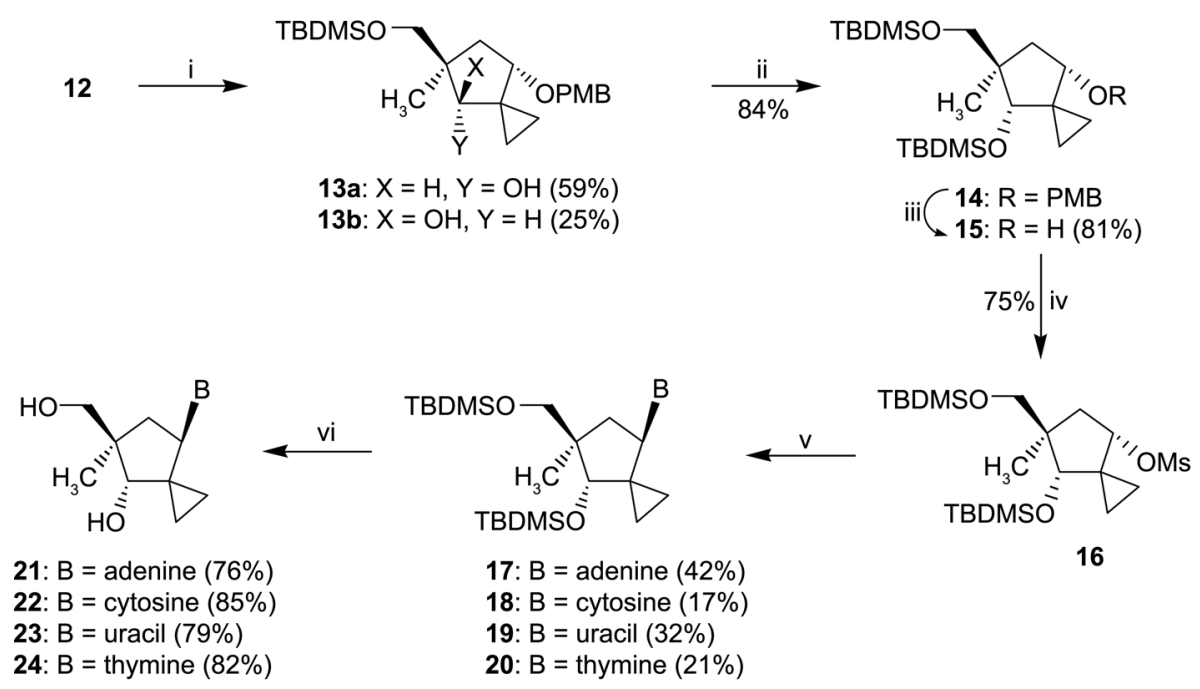

Reagents: i) $\mathrm{LiAlH}_{4}$, ether; ii) TBDMSCl, imidazole, $\mathrm{CH}_{2} \mathrm{Cl}_{2}$; iii) DDQ, $\mathrm{CH}_{2} \mathrm{Cl}_{2}, \mathrm{H}_{2} \mathrm{O}$; iv) $\mathrm{MsCl}, \mathrm{TEA}, \mathrm{CH}_{2} \mathrm{Cl}_{2}$; v) bases, $\mathrm{NaH}$, DMF; vi) TBAF, $\mathrm{THF} / \mathrm{CH}_{3} \mathrm{CN}$.

Scheme 2. Synthesis of target 4'-methyl-2'-spirocyclopropyl nucleoside analogues.

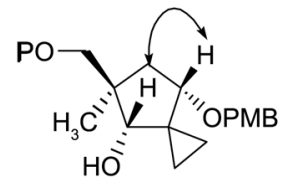

$13 \mathrm{a}(0.67 \%)$

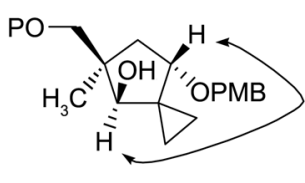

13b $(0.42 \%)$
Figure 3. NOE differences between the proximal hydrogens of 13a and $\mathbf{1 3 b}$.

$\left[\mathrm{UV}(\mathrm{MeOH}) \lambda_{\max } 279 \mathrm{~nm}\right] .{ }^{17}$ Also, $O_{2}$-isomers of pyrimidine bases such as 2-O-cyt, 2-O-ura, 2-O-thy are readily differentiated by the UV data. ${ }^{18}$ Finally, global deprotection of intermediates 17-20 with TBAF efficiently produced the targets 4'-methyl-2'-spirocyclopropylnucleosides 21-24.

The synthesized nucleoside analogues mentioned above were assayed for their ability to inhibit HCV RNA replication in a subgenomic replicon Huh7 cell line. ${ }^{19}$ This system is composed of a human hepatocarcinoma cell line supporting HCV replication. These cells contain an HCV subgenomic replicon RNA encoding a luciferase reporter gene as a marker. The antiviral potency of these analogues against the $\mathrm{HCV}$ replicon is expressed as $\mathrm{EC}_{50}$, which was quantified by a luciferase assay after a two-day incubation period with the compounds. To confirm the anti-HCV potency of compounds, subgenomic replicon RNA levels were quantified by real-time RT-PCR analysis. In addition, the associated cytotoxicity was evaluated in a tetrazolium (XTT)-based assay. As shown in Table 1, the cytosine nucleoside analogue 22 showed significant anti-HCV activity. However, nucleoside analogues $\mathbf{2 3}$ and $\mathbf{2 4}$ did not show anti$\mathrm{HCV}$ activity or cytotoxicity at concentrations of up to $50 \mu \mathrm{M}$.

In summary, based on the potent anti-HCV activity of 4'branched nucleoside and 2'-spirocyclopropyl nucleoside analogue, we have designed and successfully synthesized
Table 1. Anti-HCV activity of the newly synthesized compounds

\begin{tabular}{ccc}
\hline $\begin{array}{c}\text { Compound } \\
\text { No. }\end{array}$ & $\begin{array}{c}\text { Anti-HCV } \\
\mathrm{EC}_{50}(\mu \mathrm{M})\end{array}$ & $\begin{array}{c}\text { Cytotoxicity } \\
\mathrm{CC}_{50}(\mu \mathrm{M})\end{array}$ \\
\hline $\mathbf{2 1}$ & 39.2 & 41.3 \\
$\mathbf{2 2}$ & $\mathbf{1 8 . 2}$ & 42.5 \\
$\mathbf{2 3}$ & $>50$ & $>50$ \\
$\mathbf{2 4}$ & $>50$ & $>50$ \\
$\mathbf{2}^{\prime}$-C - -Me-C & 4.6 & $>50$ \\
\hline
\end{tabular}

2'-C-Me-C: 2'-C-Methylcytidine (Fig. 1). $\mathrm{EC}_{50}(\mu \mathrm{g} / \mathrm{mL})$ : concentration required to inhibit the replication of $\mathrm{HCV}$ in Huh-7 cell. $\mathrm{CC}_{50}(\mu \mathrm{g} / \mathrm{mL})$ : concentration required to reduce cell viability

novel 4'-methyl-2'-spirocarbocyclic nucleoside analogues starting from acetol. 2'-Spiroribonucleoside analogue ${ }^{7} \mathbf{3}$ and $4^{4}$-azidoribonucleoside analogue ${ }^{9} \mathbf{4}$ were found to inhibit $\mathrm{HCV}$ with an $\mathrm{EC}_{50}=7.3 \mu \mathrm{M}$ and $1.28 \mu \mathrm{M}$, respectively. Taking these data into account, the proposed 4'-pocket in the active site of the RNA polymerase encoded by HCV is sensitive to electronic changes in the 4'-substituent, especially when such changes involve increasing the van der Waals radius or changing the projection angle of the 4'-substituent into the pocket.

\section{Experimental Section}

Melting points were determined on a Mel-temp II laboratory device and are uncorrected. NMR spectra were recorded on a JEOL 300 Fourier transform spectrometer (JEOL, Tokyo, Japan); chemical shifts are reported in parts per million $(\delta)$ and signals are reported as s (singlet), d (doublet), t (triplet), q (quartet), m (multiplet) and dd (doublet of doublets). UV spectra were obtained on a Beckman DU-7 spectrophotometer (Beckman, South Pasadena, CA, USA). The elemental analyses were performed using a PerkinElmer 2400 analyzer (Perkin-Elmer, Norwalk, CT, USA). 
TLC was performed on Uniplates (silica gel) purchased from Analtech Co. (7558, Newark, DE, USA). All reactions were carried out in an atmosphere of nitrogen unless otherwise specified. Dry dichloromethane, benzene and pyridine were obtained by distillation from $\mathrm{CaH}_{2}$. Dry THF was obtained by distillation from $\mathrm{Na}$ and benzophenone immediately prior to use.

(rel)-(3R and $3 S, 5 S)-5$-( $t$-Butyldimethylsilanyloxymethyl)5,6-dimethyl-hepta-1,6-dien-3-ol (6): To a solution of $\mathbf{5}$ $(2.5 \mathrm{~g}, 9.75 \mathrm{mmol})$ in dry THF $(25 \mathrm{~mL})$ was slowly added vinyl $\mathrm{MgBr}\left(11.7 \mathrm{~mL}, 1.0 \mathrm{M}\right.$ solution in THF) at $-78^{\circ} \mathrm{C}$. After $5 \mathrm{~h}$, saturated $\mathrm{NH}_{4} \mathrm{Cl}$ solution $(12 \mathrm{~mL})$ and water $(70 \mathrm{~mL})$ were added sequentially, and the reaction mixture was slowly warmed to rt. The mixture was extracted with EtOAc $(70 \mathrm{~mL})$ two times. The combined organic layer was dried over $\mathrm{MgSO}_{4}$, filtered, and evaporated. The residue was purified by silica gel column chromatography (EtOAc/ hexane, $1: 12)$ to give $6(2.02 \mathrm{~g}, 73 \%)$ as colorless oil: ${ }^{1} \mathrm{H}$ NMR $\left(\mathrm{CDCl}_{3}, 300 \mathrm{MHz}\right) \delta 5.96-5.85(\mathrm{~m}, 1 \mathrm{H}), 5.30-5.14(\mathrm{~m}$, $2 \mathrm{H}), 4.72-4.64(\mathrm{~m}, 2 \mathrm{H}), 3.92(\mathrm{~m}, 2 \mathrm{H}), 3.71(\mathrm{dd}, J=10.4$, $6.8 \mathrm{~Hz}, 2 \mathrm{H}), 1.69(\mathrm{~s}, 3 \mathrm{H}), 1.46-1.39(\mathrm{~m}, 2 \mathrm{H}), 1.29(\mathrm{~s}, 3 \mathrm{H})$, $0.83(\mathrm{~m}, 9 \mathrm{H}), 0.01(\mathrm{~m}, 6 \mathrm{H})$.

(rel)-(1R and $1 S, 4 S)-4$-( $t$-Butyldimethylsilyloxymethyl)3,4-dimethyl-cyclopent-2-enol (7): To a solution of $6(1.22 \mathrm{~g}$, $4.30 \mathrm{mmol})$ in dry benzene $(10 \mathrm{~mL})$ was added $2^{\text {nd }}$ generation Grubbs catalyst $(63 \mathrm{mg} 0.075 \mathrm{mmol})$. The reaction mixture was refluxed overnight and cooled to room temperature. The mixture was concentrated in vacuo, and the residue was purified by silica gel column chromatography (EtOAc/ hexane, 1:10) to give cyclopentenol $7(860 \mathrm{mg}, 78 \%)$ as a diastereomeric mixture. ${ }^{1} \mathrm{H}$ NMR $\left(\mathrm{CDCl}_{3}, 300 \mathrm{MHz}\right) \delta 5.41$ $5.38(\mathrm{~m}, 2 \mathrm{H}), 4.08(\mathrm{~m}, 2 \mathrm{H}), 3.79-3.53(\mathrm{~m}, 4 \mathrm{H}), 1.95(\mathrm{~m}, 2 \mathrm{H})$, 1.79-1.74 (m, 5H), $1.65(\mathrm{~s}, 3 \mathrm{H}), 1.31(\mathrm{~s}, 3 \mathrm{H}), 1.27(\mathrm{~s}, 3 \mathrm{H})$, $0.82(\mathrm{~m}, 18 \mathrm{H}), 0.01(\mathrm{~m}, 12 \mathrm{H})$.

$( \pm)-4-(t$-Butyldimethylsilanyloxymethyl)-3,4-dimethylcyclopent-2-enone (8): A mixture of allylic alcohol 7 (1.37 g, $5.34 \mathrm{mmol})$ and manganese (IV) dioxide $(1.28 \mathrm{~g}, 14.8 \mathrm{mmol})$ in $\mathrm{CCl}_{4}(20 \mathrm{~mL})$ was stirred at $65^{\circ} \mathrm{C}$. Additional manganese (IV) dioxide (214 mg, $2.47 \mathrm{mmol}$ ) was added each hour and the progress of the reaction was monitored by TLC (EtOAc/ hexane, 1:30). The resultant mixture was filtered through a pad of Celite and washed with ethyl acetate. The filtrate and washes were concentrated in vacuo to give a residue that was purified by silica gel column chromatography (EtOAc/ hexane, $1: 30)$ to give $\alpha, \beta$-unsaturated ketone derivative $\mathbf{8}$ (937 mg, 69\%) as a colorless oil. ${ }^{1} \mathrm{H} \mathrm{NMR}\left(\mathrm{CDCl}_{3}, 300 \mathrm{MHz}\right)$ $\delta 5.79(\mathrm{~d}, J=5.2 \mathrm{~Hz}, 1 \mathrm{H}), 3.77(\mathrm{~d}, J=10.6 \mathrm{~Hz}, 1 \mathrm{H}), 3.47(\mathrm{~d}$, $J=10.7 \mathrm{~Hz}, 1 \mathrm{H}), 2.88$ (d, $J=8.8 \mathrm{~Hz}, 1 \mathrm{H}), 2.57$ (d, $J=8.9$ $\mathrm{Hz}, 1 \mathrm{H}), 1.77$ (s, 3H), 1.31 (s, 3H), 0.82 (s, 9H), 0.02 (s, $6 \mathrm{H}) ;{ }^{13} \mathrm{C}$ NMR $\left(\mathrm{CDCl}_{3}, 75 \mathrm{MHz}\right) \delta 198.4,161.9,117.3$, 75.2, 53.0, 41.5, 25.3, 21.3, 18.4, 16.8, -5.7; Anal. Calcd. for $\mathrm{C}_{14} \mathrm{H}_{26} \mathrm{O}_{2} \mathrm{Si}: \mathrm{C}, 66.09 ; \mathrm{H}, 10.30$. Found: $\mathrm{C}, 66.13 ; \mathrm{H}, 10.26$.

( \pm -6-( $t$-Butyldimethylsilanyloxymethyl)-6-methyl-7methylene-spiro[2.4] heptan-4-one (9); and ( \pm )-7-( $t$ butyldimethylsilanyloxymethyl)-6,7-dimethyl-spiro[2.4] hept5-en-4-one (9'): A solution of bicyclic enone 8 (346 mg, $1.36 \mathrm{mmol})$ in $t$-butyl alcohol $(4.0 \mathrm{~mL})$ was added to a stirred mixture of potassium $t$-butoxide $(615 \mathrm{mg}, 5.5 \mathrm{mmol})$ in $t$-butyl alcohol $(4.0 \mathrm{~mL})$. After the mixture was stirred at room temperature for $20 \mathrm{~min}$, potassium iodide $(455 \mathrm{mg}$, $2.75 \mathrm{mmol}$ ) and (2-chloroethyl)dimethylsulfonium iodide (640 mg, $2.55 \mathrm{mmol}$ ) were added in portions under a stream of nitrogen. The mixture was stirred at room temperature for $1.5 \mathrm{~h}$, diluted with saturated $\mathrm{NH}_{4} \mathrm{Cl}$ solution $(20 \mathrm{~mL})$, and extracted with ether $(3 \times 30 \mathrm{~mL})$. The combined organic layer was washed with brine, dried under anhydrous magnesium sulfate and concentrated. The residue was purified by column chromatography (EtOAc/hexane, 1:25) on silica gel to give ketones 9 (110 $\mathrm{mg}, 29 \%)$ and $\mathbf{9}^{\prime}(129 \mathrm{mg}, 34 \%)$ as colorless oil. Spectral date for 9: ${ }^{1} \mathrm{H}$ NMR $\left(\mathrm{CDCl}_{3}, 300 \mathrm{MHz}\right)$ $\delta 4.71(\mathrm{br} \mathrm{s}, 1 \mathrm{H}), 4.61(\mathrm{br} \mathrm{s}, 1 \mathrm{H}), 3.65(\mathrm{~d}, J=9.4 \mathrm{~Hz}, 1 \mathrm{H})$, $3.44(\mathrm{~d}, J=9.5 \mathrm{~Hz}, 1 \mathrm{H}), 2.88(\mathrm{~d}, J=8.8 \mathrm{~Hz}, 1 \mathrm{H}), 2.57$ (d, $J$ $=8.9 \mathrm{~Hz}, 1 \mathrm{H}), 1.31(\mathrm{~s}, 3 \mathrm{H}), 1.20-0.91(\mathrm{~m}, 4 \mathrm{H}), 0.82(\mathrm{~s}, 9 \mathrm{H})$, $0.01(\mathrm{~s}, 6 \mathrm{H}) ;{ }^{13} \mathrm{C}$ NMR $\left(\mathrm{CDCl}_{3}, 75 \mathrm{MHz}\right) \delta 210.7,167.2$, 95.4, 77.0, 47.7, 39.5, 32.6, 25.5, 20.7, 18.3, 10.8, 9.4, -5.2; Anal. Calcd. for $\mathrm{C}_{16} \mathrm{H}_{28} \mathrm{O}_{2} \mathrm{Si}$ : C, 68.52; H, 10.06. Found: C, 68.47; $\mathrm{H}, 10.11$. Spectral data for 9': ${ }^{1} \mathrm{H}$ NMR $\left(\mathrm{CDCl}_{3}, 300\right.$ MHz) $\delta 5.87(\mathrm{~s}, 1 \mathrm{H}), 3.75(\mathrm{~d}, J=9.2 \mathrm{~Hz}, 1 \mathrm{H}), 3.62(\mathrm{~d}, J=$ $9.3 \mathrm{~Hz}, 1 \mathrm{H}), 1.74(\mathrm{~s}, 3 \mathrm{H}), 1.28(\mathrm{~s}, 3 \mathrm{H}), 1.16-0.89(\mathrm{~m}, 4 \mathrm{H})$, 0.81 (s, 9H), $0.02(\mathrm{~s}, 6 \mathrm{H}) ;{ }^{13} \mathrm{C} \mathrm{NMR}\left(\mathrm{CDCl}_{3}, 75 \mathrm{MHz}\right) \delta 202.2$, 156.4, 123.5, 69.4, 56.2, 40.6, 25.3, 22.0, 18.7, 12.8, 11.1, 9.8, -5.5; Anal. Calcd. for $\mathrm{C}_{16} \mathrm{H}_{28} \mathrm{O}_{2} \mathrm{Si}: \mathrm{C}, 68.52 ; \mathrm{H}, 10.06$. Found: C, 68.55; H, 10.04 .

(rel)-(4S,6R)-6-(t-Butyldimethylsilanyloxymethyl)-6methyl-7-methylenespiro[2.4] heptan-4-ol (10a) and (rel)(4R,6R)-6-( $t$-butyldimethylsilanyloxymethyl)-6-methyl-7methylene-spiro[2.4]heptan-4-ol (10b): A $1.0 \mathrm{M}$ solution of lithium aluminum hydride in ether $(0.6 \mathrm{~mL}, 0.6 \mathrm{mmol})$ was added to a solution of ketone $9(129 \mathrm{mg}, 0.46 \mathrm{mmol})$ in ether $(5 \mathrm{~mL})$. The mixture was stirred at room temperature (rt) for $40 \mathrm{~min}$. To the cooled reaction mixture was added a solution of $\mathrm{H}_{2} \mathrm{O} / \mathrm{THF}(1: 9)(6.0 \mathrm{~mL})$, and the mixture was stirred at room temperature for $45 \mathrm{~min}$ and filtered through a pad of Celite. The residue was thoroughly washed with ether, and the filtrate and the washes were combined and concentrated. The residual oil was purified by column chromatography (EtOAc/hexane, 1:15) on silica gel to give alcohol 10a $(55.8 \mathrm{mg}, 43 \%)$ and $\mathbf{1 0 b}(53 \mathrm{mg}, 41 \%)$ as colorless oils. Compound 10a: ${ }^{1} \mathrm{H}$ NMR $\left(\mathrm{CDCl}_{3}, 300 \mathrm{MHz}\right) \delta 4.74(\mathrm{~d}, J=$ $2.1 \mathrm{~Hz}, 1 \mathrm{H}), 4.66(\mathrm{~d}, J=2.2 \mathrm{~Hz}, 1 \mathrm{H}), 3.69(\mathrm{~d}, J=9.6 \mathrm{~Hz}$, $1 \mathrm{H}), 3.48$ (d, $J=9.6 \mathrm{~Hz}, 1 \mathrm{H}), 3.27$ (dd, $J=6.8,4.8 \mathrm{~Hz}, 1 \mathrm{H}$ ), $1.50(\mathrm{dd}, J=8.8,6.8 \mathrm{~Hz}, 1 \mathrm{H}), 1.44(\mathrm{dd}, J=8.9,4.8 \mathrm{~Hz}, 1 \mathrm{H})$, $1.22(\mathrm{~s}, 3 \mathrm{H}), 0.94-1.19(\mathrm{~m}, 4 \mathrm{H}), 0.82(\mathrm{~s}, 9 \mathrm{H}), 0.01(\mathrm{~s}, 6 \mathrm{H})$; ${ }^{13} \mathrm{C} \mathrm{NMR}\left(\mathrm{CDCl}_{3}, 75 \mathrm{MHz}\right) \delta 165.4,106.4,86.0,75.1,44.3$, 32.3, 25.6, 19.2, 18.3, 11.0, 8.8, -5.5; Anal. Calcd. for $\mathrm{C}_{16} \mathrm{H}_{30} \mathrm{O}_{2} \mathrm{Si}: \mathrm{C}, 68.03 ; \mathrm{H}, 10.70$. Found: C, 67.95; H, 10.65; Compound 10b: ${ }^{1} \mathrm{H}$ NMR $\left(\mathrm{CDCl}_{3}, 300 \mathrm{MHz}\right) \delta 4.75(\mathrm{~d}, J=$ $1.9 \mathrm{~Hz}, 1 \mathrm{H}), 4.63(\mathrm{~d}, J=2.0 \mathrm{~Hz}, 1 \mathrm{H}), 3.71(\mathrm{~d}, J=10.1 \mathrm{~Hz}$, $1 \mathrm{H}), 3.46(\mathrm{~d}, J=9.9 \mathrm{~Hz}, 1 \mathrm{H}), 3.21(\mathrm{dd}, J=6.8,4.4 \mathrm{~Hz}, 1 \mathrm{H})$, $1.56(\mathrm{dd}, J=8.8,6.7 \mathrm{~Hz}, 1 \mathrm{H}), 1.41(\mathrm{~m}, 1 \mathrm{H}), 1.24(\mathrm{~s}, 3 \mathrm{H})$, $1.18-0.88(\mathrm{~m}, 4 \mathrm{H}), 0.81(\mathrm{~s}, 9 \mathrm{H}), 0.02(\mathrm{~s}, 6 \mathrm{H}) ;{ }^{13} \mathrm{C}$ NMR $\left(\mathrm{CDCl}_{3}, 75 \mathrm{MHz}\right) \delta 166.5,108.4,84.7,74.8,46.0,33.5$, 25.3, 19.3, 18.5, 10.8, 8.9, -5.3; Anal. Calcd. for $\mathrm{C}_{16} \mathrm{H}_{30} \mathrm{O}_{2} \mathrm{Si}$ : C, 68.03; H, 10.70. Found: C, 68.09; H, 10.73 . 
(rel)-(5S,7S)-6-t-Butyl-[7-(4-methoxybenzyloxy)-5-methyl4-methylenespiro[2.4]hept-5-ylmethoxy]-dimethylsilane (11): $\mathrm{NaH}(60 \%$ in mineral oil, $1.66 \mathrm{~g}, 41.6 \mathrm{mmol})$ was added portion-wise to a cooled $\left(0{ }^{\circ} \mathrm{C}\right)$ solution of $10 \mathrm{a}(9.79$ g, $34.67 \mathrm{mmol})$ in DMF $(100 \mathrm{~mL})$ and $p$-methoxybenzyl chloride $(5.17 \mathrm{~mL}, 38.13 \mathrm{mmol})$ in anhydrous DMF $(50 \mathrm{~mL})$. The reaction mixture was stirred at $\mathrm{rt}$ overnight. The solvent was quenched with $\mathrm{H}_{2} \mathrm{O}$, removed under reduced pressure and extracted with EtOAc $(2 \times 100 \mathrm{~mL})$. The combined organic layer was washed with brine, dried over anhydrous $\mathrm{MgSO}_{4}$, and concentrated under reduced pressure. The residue was purified by silica gel column chromatography (EtOAc/hexane, 1:10) to give $11(10.88 \mathrm{~g}, 78 \%)$ as a colorless oil. ${ }^{1} \mathrm{H}$ NMR $\left(\mathrm{CDCl}_{3}, 300 \mathrm{MHz}\right) \delta$ 7.27-7.23 (m, 2H), 6.91-6.83 (m, 2H), 4.75 (d, $J=2.0 \mathrm{~Hz}, 1 \mathrm{H}), 4.64$ (br s, 1H), 4.44 (s, 2H), 3.82 (s, 3H), 3.67 (d, $J=9.8 \mathrm{~Hz}, 1 \mathrm{H}), 3.49$ $(\mathrm{d}, J=9.8 \mathrm{~Hz}, 1 \mathrm{H}), 2.86(\mathrm{dd}, J=6.2,5.0 \mathrm{~Hz}, 1 \mathrm{H}), 1.39(\mathrm{dd}, J$ $=10.6,8.8 \mathrm{~Hz}, 1 \mathrm{H}), 1.23(\mathrm{dd}, J=10.7,6.8 \mathrm{~Hz}, 1 \mathrm{H}), 1.27(\mathrm{~s}$, $3 \mathrm{H}), 1.19-0.95(\mathrm{~m}, 4 \mathrm{H}), 0.81(\mathrm{~s}, 9 \mathrm{H}), 0.02(\mathrm{~s}, 6 \mathrm{H}) ;{ }^{13} \mathrm{C} \mathrm{NMR}$ $\left(\mathrm{CDCl}_{3}, 75 \mathrm{MHz}\right) \delta 166.6,159.3,131.2,129.0,116.3,102.5$, 89.3, 75.3, 45.7, 42.3, 30.8, 25.3, 19.0, 18.5, 10.6, 8.9, -5.4; Anal. Calcd. for $\mathrm{C}_{24} \mathrm{H}_{38} \mathrm{O}_{3} \mathrm{Si}$ : C, 71.59; H, 9.51. Found: C, $71.63 ; \mathrm{H}, 9.46$.

(rel)-(5S,7S)-5-(t-Butyldimethylsilanyloxymethyl)-7-(4methoxybenzyloxy)-5-methyl-spiro[2.4]heptan-4-one (12): A solution of compound $11(3.87 \mathrm{~g}, 9.62 \mathrm{mmol})$ in anhydrous $\mathrm{CH}_{2} \mathrm{Cl}_{2}(50 \mathrm{~mL})$ was cooled to $-78^{\circ} \mathrm{C}$, and ozone gas was then bubbled into the reaction mixture until a blue color persisted for 10 minutes. The reaction mixture was degassed with nitrogen, and dimethyl sulfide $(2.97 \mathrm{~mL}$, $40.41 \mathrm{mmol}$ ) was slowly added at $-78^{\circ} \mathrm{C}$. The mixture was stirred for $1 \mathrm{~h}$ at $-78{ }^{\circ} \mathrm{C}$ under argon gas and concentrated under reduced pressure. The residue was purified by silica gel column chromatography (EtOAc/hexane, 1:12) to give compound $12(2.96 \mathrm{~g}, 76 \%)$ as a colorless oil. ${ }^{1} \mathrm{H}$ NMR $\left(\mathrm{CDCl}_{3}, 300 \mathrm{MHz}\right) \delta 7.28-7.24(\mathrm{~m}, 2 \mathrm{H}), 6.93-6.85(\mathrm{~m}, 2 \mathrm{H})$, $4.65(\mathrm{~s}, 2 \mathrm{H}), 3.97$ (d, $J=9.9 \mathrm{~Hz}, 1 \mathrm{H}), 3.82(\mathrm{~d}, J=9.8 \mathrm{~Hz}$, $1 \mathrm{H}), 3.78$ (s, 3H), 3.39 (dd, $J=5.8,4.2 \mathrm{~Hz}, 1 \mathrm{H}), 2.26$ (dd, $J$ $=10.8,8.2 \mathrm{~Hz}, 1 \mathrm{H}), 2.09(\mathrm{dd}, J=10.8,6.7 \mathrm{~Hz}, 1 \mathrm{H}), 1.28(\mathrm{~s}$, $3 \mathrm{H}), 1.16-0.91(\mathrm{~m}, 4 \mathrm{H}), 0.82(\mathrm{~s}, 9 \mathrm{H}), 0.01(\mathrm{~s}, 6 \mathrm{H}) ;{ }^{13} \mathrm{C} \mathrm{NMR}$ $\left(\mathrm{CDCl}_{3}, 75 \mathrm{MHz}\right) \delta 214.2,159.7,132.5,130.5,117.7,73.8$, 73.1, 69.8, 53.1, 37.5, 28.5, 25.6, 18.4, 16.3, 11.2, 9.2, -5.6; Anal. Calcd. for $\mathrm{C}_{23} \mathrm{H}_{36} \mathrm{O}_{4} \mathrm{Si}$ : C, 68.27; H, 8.97. Found: C, $68.33 ; \mathrm{H}, 8.91$.

(rel)-(4S,5S,7S)-5-(t-Butyldimethylsilanyloxymethyl)-7(4-methoxybenzyloxy)-5-methyl-spiro[2.4]heptan-4-ol (13a) and (rel)-(4R,5S,7S)-5-( $t$-butyldimethylsilanyloxymethyl)-7(4-methoxybenzyloxy)-5-methyl-spiro[2.4]heptan-4-ol (13b): Compounds 13a and 13b were synthesized from 12 using a similar procedure as described for 10a and 10b. Spectral data for 13a: yield 59\%; ${ }^{1} \mathrm{H} \mathrm{NMR}\left(\mathrm{CDCl}_{3}, 300 \mathrm{MHz}\right) \delta$ 7.25-7.20 (m, 2H), 6.89-6.84 (m, 2H), $4.65(\mathrm{~s}, 2 \mathrm{H}), 3.77(\mathrm{~s}$, $3 \mathrm{H}), 3.70(\mathrm{~d}, J=8.8 \mathrm{~Hz}, 1 \mathrm{H}), 3.61(\mathrm{~d}, J=8.9 \mathrm{~Hz}, 1 \mathrm{H}), 3.22$ (s, 1H), $2.87(\mathrm{~m}, 1 \mathrm{H}), 1.62(\mathrm{dd}, J=10.2,8.4 \mathrm{~Hz}, 1 \mathrm{H}), 1.49$ (dd, $J=10.3,6.6 \mathrm{~Hz}, 1 \mathrm{H}), 1.13$ (s, 3H), 1.13-0.89 (m, 4H), $0.82(\mathrm{~s}, 9 \mathrm{H}), 0.01(\mathrm{~s}, 6 \mathrm{H}) ;{ }^{13} \mathrm{C} \mathrm{NMR}\left(\mathrm{CDCl}_{3}, 75 \mathrm{MHz}\right) \delta$ 159.5, 131.8, 129.7, 119.2, 77.2, 75.4, 71.4, 35.8, 31.2, 29.4,
25.6, 18.4, 15.7, 10.6, 8.8, -5.3; Anal. Calcd. for $\mathrm{C}_{23} \mathrm{H}_{38} \mathrm{O}_{4} \mathrm{Si}$ : C, 67.94; H, 9.42. Found: C, 67.89; H, 9.37; Spectral data for 13b: yield $25 \%$; ${ }^{1} \mathrm{H} \mathrm{NMR}\left(\mathrm{CDCl}_{3}, 300 \mathrm{MHz}\right) \delta 7.26-7.19$ (m, 2H), 6.90-6.85 (m, 2H), $4.64(\mathrm{~s}, 2 \mathrm{H}), 3.79$ (s, 3H), 3.73 $(\mathrm{d}, J=9.0 \mathrm{~Hz}, 1 \mathrm{H}), 3.61(\mathrm{~d}, J=8.9 \mathrm{~Hz}, 1 \mathrm{H}), 3.20(\mathrm{~s}, 1 \mathrm{H})$, $2.87(\mathrm{~m}, 1 \mathrm{H}), 1.63(\mathrm{dd}, J=10.6,8.5 \mathrm{~Hz}, 1 \mathrm{H}), 1.50(\mathrm{dd}, J=$ 10.5, $6.8 \mathrm{~Hz}, 1 \mathrm{H}), 1.17$ (s, 3H), 1.17-0.91 (m, 4H), 0.81 (s, 9H), $0.02(\mathrm{~s}, 6 \mathrm{H}) ;{ }^{13} \mathrm{C} \mathrm{NMR}\left(\mathrm{CDCl}_{3}, 75 \mathrm{MHz}\right) \delta 159.7$, 132.1, 130.3, 118.4, 78.5, 74.3, 70.8, 36.5, 31.2, 28.7, 25.4, 18.5, 14.9, 10.8, 8.9, -5.6; Anal. Calcd. for $\mathrm{C}_{23} \mathrm{H}_{38} \mathrm{O}_{4} \mathrm{Si}: \mathrm{C}$, 67.94; H, 9.42. Found: C, 67.97; H, 9.46.

(rel)-(4S,5S,7S)-4-(t-Butyldimethylsilanyloxy)-5-(t-butyldimethylsilanyloxymethyl)-7-(4-methoxy benzyloxy)-5methyl-spiro[2.4]heptanes (14): TBDMSCl (1.16 g, 7.71 mmol) was added slowly to a solution of 13a (2.85 g, 7.02 mmol) and imidazole $(0.72 \mathrm{~g}, 10.52 \mathrm{mmol})$ in $\mathrm{CH}_{2} \mathrm{Cl}_{2}(150 \mathrm{~mL})$ at $0{ }^{\circ} \mathrm{C}$, and stirred for $5 \mathrm{~h}$ at the same temperature. The solvent was evaporated under reduced pressure. The residue was dissolved in water $(150 \mathrm{~mL})$ and extracted with diethyl ether $(150 \mathrm{~mL})$. The organic layer was washed with brine, dried over anhydrous $\mathrm{MgSO}_{4}$, filtered, and concentrated under reduced pressure. The residue was purified by silica gel column chromatography (EtOAc/hexane, 1:18) to give compound $14(3.07 \mathrm{~g}, 84 \%)$ as a colorless oil. ${ }^{1} \mathrm{H}$ NMR $\left(\mathrm{CDCl}_{3}, 300 \mathrm{MHz}\right) \delta$ 7.27-7.21 (m, 2H), 6.93-6.87 (m, 2H), 4.65 (s, 2H), 3.82 (s, 3H), $3.75(\mathrm{~d}, J=9.2 \mathrm{~Hz}, 1 \mathrm{H}), 3.56$ (d, $J$ $=9.1 \mathrm{~Hz}, 1 \mathrm{H}), 3.19(\mathrm{~s}, 1 \mathrm{H}), 2.85(\mathrm{~m}, 1 \mathrm{H}), 1.84(\mathrm{dd}, J=10.8$, $8.8 \mathrm{~Hz}, 1 \mathrm{H}), 1.62(\mathrm{dd}, J=10.7,6.8 \mathrm{~Hz}, 1 \mathrm{H}), 1.19$ (s, 3H), 1.17$0.91(\mathrm{~m}, 4 \mathrm{H}), 0.82(\mathrm{~s}, 18 \mathrm{H}), 0.02(\mathrm{~s}, 12 \mathrm{H}) ;{ }^{13} \mathrm{C} \mathrm{NMR}\left(\mathrm{CDCl}_{3}\right.$, $75 \mathrm{MHz}) \delta 160.1,132.7,129.9,118.7,79.6,75.1,71.4,37.2$, 33.5, 29.5, 25.7, 25.1, 18.8, 13.5, 11.2, 9.2, -5.7; Anal. Calcd. for $\mathrm{C}_{29} \mathrm{H}_{52} \mathrm{O}_{4} \mathrm{Si}_{2}$ : C, 66.87; H, 10.06. Found: C, 66.91; $\mathrm{H}, 10.12$.

(rel)-(4S,6S,7S)-7-(t-Butyldimethylsilanyloxy)-6-( $t$-butyldimethylsilanyloxymethyl)-6-methyl-spiro[2.4]heptan-4-ol (15): To a solution of compound $14(1.41 \mathrm{~g}, 2.71 \mathrm{mmol})$ in $\mathrm{CH}_{2} \mathrm{Cl}_{2} / \mathrm{H}_{2} \mathrm{O}$ mixture $(12 \mathrm{~mL}, 20: 1 \mathrm{v} / \mathrm{v})$ was added DDQ (672 mg, $3.69 \mathrm{mmol}$ ) and the mixture was stirred for $4 \mathrm{~h}$ at room temperature. Saturated $\mathrm{NaHCO}_{3}(3 \mathrm{~mL})$ was added to quench the reaction and further diluted with water $(50 \mathrm{~mL})$. The organic layer was separated, washed with brine, dried over anhydrous $\mathrm{MgSO}_{4}$, and filtered. The filtrate was concentrated under reduced pressure and the residue was purified by silica gel column chromatography (EtOAc/ hexane, 1:15) to give compound $\mathbf{1 5}(879 \mathrm{mg}, 81 \%)$ as a colorless oil. ${ }^{1} \mathrm{H}$ NMR $\left(\mathrm{CDCl}_{3}, 300 \mathrm{MHz}\right) \delta 3.70(\mathrm{~d}, J=9.1 \mathrm{~Hz}, 1 \mathrm{H})$, $3.58(\mathrm{~d}, J=9.0 \mathrm{~Hz}, 1 \mathrm{H}), 3.24(\mathrm{~m}, 1 \mathrm{H}), 3.19(\mathrm{~s}, 1 \mathrm{H}), 1.62$ $(\mathrm{dd}, J=10.8,8.6 \mathrm{~Hz}, 1 \mathrm{H}), 1.52(\mathrm{dd}, J=10.8,6.8 \mathrm{~Hz}, 1 \mathrm{H})$, $1.15(\mathrm{~s}, 3 \mathrm{H}), 1.18-0.90(\mathrm{~m}, 4 \mathrm{H}), 0.81(\mathrm{~s}, 18 \mathrm{H}), 0.01(\mathrm{~s}, 12 \mathrm{H})$; ${ }^{13} \mathrm{C} \mathrm{NMR}\left(\mathrm{CDCl}_{3}, 75 \mathrm{MHz}\right) \delta 84.5,72.5,70.6,36.7,32.9,31.1$, 25.5, 18.3, 15.2, 10.8, 8.8, -5.3; Anal. Calcd. for $\mathrm{C}_{21} \mathrm{H}_{44} \mathrm{O}_{3} \mathrm{Si}_{2}$. 0.5 EtOAc: C, 61.10; H, 10.87. Found: C, 61.08; H, 10.89 .

(rel)-(4S,6S,7S)-7-(t-Butyldimethylsilanyloxy)-6-(t-butyldimethylsilanyloxymethyl)-6-methylspiro[2.4]heptyl-4methansulfonate (16): A solution of $15(240 \mathrm{mg}, 0.6 \mathrm{mmol})$ and $\mathrm{Et}_{3} \mathrm{~N}(0.252 \mathrm{~mL}, 1.8 \mathrm{mmol})$ in $\mathrm{CH}_{2} \mathrm{Cl}_{2}(25 \mathrm{~mL})$ was cooled to $0{ }^{\circ} \mathrm{C}$ and treated dropwise with $\mathrm{MsCl}(96 \mu \mathrm{L}, 1.2 \mathrm{mmol})$. 
The reaction mixture was stirred for $4 \mathrm{~h}$, allowed to warm to rt, quenched with saturated $\mathrm{NaHCO}_{3}$ solution $(1.0 \mathrm{~mL})$, and further diluted with water $(80 \mathrm{~mL})$. The mixture was extracted with $\mathrm{Et}_{2} \mathrm{O}(3 \times 80 \mathrm{~mL})$. The combined organic phases were dried and concentrated. The residue was purified by silica gel column chromatography (EtOAc/hexane, $1: 15)$ to give compound $\mathbf{1 6}(879 \mathrm{mg}, 75 \%)$ as a colorless oil. ${ }^{1} \mathrm{H}$ NMR $\left(\mathrm{CDCl}_{3}, 300 \mathrm{MHz}\right) \delta 4.81(\mathrm{dd}, J=5.0,2.8 \mathrm{~Hz}, 1 \mathrm{H})$, $3.72(\mathrm{~d}, J=9.2 \mathrm{~Hz}, 1 \mathrm{H}), 3.61(\mathrm{~d}, J=9.3 \mathrm{~Hz}, 1 \mathrm{H}), 3.21$ (s, $1 \mathrm{H}), 3.01$ (s, 3H), 1.64 (dd, $J=10.8,8.7 \mathrm{~Hz}, 1 \mathrm{H}), 1.50$ (dd, $J$ $=10.9,6.8 \mathrm{~Hz}, 1 \mathrm{H}), 1.17(\mathrm{~s}, 3 \mathrm{H}), 1.21-0.92(\mathrm{~m}, 4 \mathrm{H}), 0.81$ $(\mathrm{m}, 18 \mathrm{H}), 0.02(\mathrm{~m}, 12 \mathrm{H}) ;{ }^{13} \mathrm{C} \mathrm{NMR}\left(\mathrm{CDCl}_{3}, 75 \mathrm{MHz}\right) \delta 83.7$, 71.2, 69.5, 38.7, 37.2, 30.4, 28.4, 25.6, 18.6, 15.7, 12.1, 9.5, -5.6 .

(rel)-(4S,6S,7S)-9-[7-(t-Butyldimethylsilanyloxy)-6-( $t$ butyldimethylsilanyloxymethyl) 6-methylspiro[2.4]hept-4-yl] adenine (17): To a mixture of $\mathrm{NaH}(12 \mathrm{mg}, 0.5 \mathrm{mmol})$ and adenine $(67 \mathrm{mg}, 0.5 \mathrm{mmol})$ in DMF $(5.5 \mathrm{~mL})$, the mesylate $16(153 \mathrm{mg}, 0.32 \mathrm{mmol})$ dissolved in DMF $(2.0 \mathrm{~mL})$ was added. The reaction mixture was brought to $80^{\circ} \mathrm{C}$, stirred for $12 \mathrm{~h}$, allowed to cool to rt, quenched with saturated $\mathrm{NaHCO}_{3}$ $(1.0 \mathrm{~mL})$ solution, and further diluted with water $(50 \mathrm{~mL})$. The mixture was extracted with ether $(3 \times 50 \mathrm{~mL})$. The combined ether layers were dried and concentrated to leave a residue that was purified by silica gel column chromatography (EtOAc/hexane, 1:1) to give compound 17 (69 $\mathrm{mg}, 42 \%$ ) as a white solid. mp $189-192{ }^{\circ} \mathrm{C}$; UV $(\mathrm{MeOH}) \lambda_{\max } 261.5 \mathrm{~nm}$; ${ }^{1} \mathrm{H} \mathrm{NMR}\left(\mathrm{CDCl}_{3}, 300 \mathrm{MHz}\right) \delta 8.28(\mathrm{~s}, 1 \mathrm{H}), 8.16(\mathrm{~s}, 1 \mathrm{H})$, $3.76(\mathrm{~d}, J=10.2 \mathrm{~Hz}, 1 \mathrm{H}), 3.69-3.61(\mathrm{~m}, 2 \mathrm{H}), 3.20(\mathrm{~s}, 1 \mathrm{H})$, 1.90 (dd, $J=11.2,8.8 \mathrm{~Hz}, 1 \mathrm{H}), 1.61$ (dd, $J=11.2,6.8 \mathrm{~Hz}$, $1 \mathrm{H}), 1.28(\mathrm{~s}, 3 \mathrm{H}), 1.12-0.93(\mathrm{~m}, 4 \mathrm{H}), 0.82(\mathrm{~m}, 18 \mathrm{H}), 0.01$ $(\mathrm{m}, 12 \mathrm{H}) ;{ }^{13} \mathrm{C} \mathrm{NMR}\left(\mathrm{CDCl}_{3}, 75 \mathrm{MHz}\right) \delta 156.2,152.3,145.7$, $132.4,119.4,86.1,70.7,57.6,39.3,29.7,27.7,25.6,18.6$, 15.7, 10.0, 8.6, -5.3; Anal. Calcd. for $\mathrm{C}_{26} \mathrm{H}_{47} \mathrm{~N}_{5} \mathrm{O}_{2} \mathrm{Si}_{2}: \mathrm{C}$, $60.30 ; \mathrm{H}, 9.15 ; \mathrm{N}, 13.52$. Found: C, 60.25; H, 9.11; N, 13.47.

(rel)-(4S,6S,7S)-1-[7-(t-Butyldimethylsilanyloxy)-6-(tbutyldimethylsilanyloxymethyl) 6-methylspiro[2.4]hept4-yl] cytosine (18): Similar coupling conditions as described for adenine synthesis $\mathbf{1 7}$ were used for the preparation of the cytosine analogue from mesylate 16. Yield 17\%; mp 160$162{ }^{\circ} \mathrm{C}$; UV (MeOH) $\lambda_{\max } 272.0 \mathrm{~nm} ;{ }^{1} \mathrm{H} \mathrm{NMR}\left(\mathrm{CDCl}_{3}, 300\right.$ $\mathrm{MHz}) \delta 8.04(\mathrm{~d}, J=5.6 \mathrm{~Hz}, 1 \mathrm{H}), 6.09(\mathrm{~d}, J=5.7 \mathrm{~Hz}, 1 \mathrm{H})$, $3.71(\mathrm{~d}, J=10.2 \mathrm{~Hz}, 1 \mathrm{H}), 3.65(\mathrm{~d}, J=10.3 \mathrm{~Hz}, 1 \mathrm{H}), 3.60$ (m, $1 \mathrm{H}), 3.22(\mathrm{~s}, 1 \mathrm{H}), 1.89(\mathrm{dd}, J=10.8,8.9 \mathrm{~Hz}, 1 \mathrm{H}), 1.72(\mathrm{dd}, J$ $=10.7,6.8 \mathrm{~Hz}, 1 \mathrm{H}), 1.35(\mathrm{~s}, 3 \mathrm{H}), 1.19-0.90(\mathrm{~m}, 4 \mathrm{H}), 0.81$ $(\mathrm{m}, 18 \mathrm{H}), 0.02(\mathrm{~m}, 12 \mathrm{H}) ;{ }^{13} \mathrm{C} \mathrm{NMR}\left(\mathrm{CDCl}_{3}, 75 \mathrm{MHz}\right) \delta$ 164.8, 163.2, 157.7, 99.6, 86.4, 70.6, 60.2, 39.6, 30.5, 28.3, 25.7, 18.8, 15.8, 12.3, 9.2, -5.6; Anal. Calcd. for $\mathrm{C}_{25} \mathrm{H}_{47} \mathrm{~N}_{3} \mathrm{O}_{3} \mathrm{Si}_{2}$ -0.5 EtOAc: C, 60.28; H, 9.50; N, 8.81. Found: C, 60.31; H, $9.48 ; \mathrm{N}, 8.79$

(rel)-(4S,6S,7S)-1-[7-(t-Butyldimethylsilanyloxy)-6-(tbutyldimethylsilanyloxymethyl) 6-methylspiro[2.4]hept-4yl] uracil (19): Uracil nucleoside analogue was synthesized from mesylate 16 using a similar procedure as described for 17. Yield $32 \%$; mp $154-156{ }^{\circ} \mathrm{C}$; UV (MeOH) $\lambda_{\max } 262.5 \mathrm{~nm}$; ${ }^{1} \mathrm{H} \mathrm{NMR}\left(\mathrm{CDCl}_{3}, 300 \mathrm{MHz}\right) \delta 8.48($ br s, $1 \mathrm{H}), 7.19(\mathrm{~d}, J=$ $8.0 \mathrm{~Hz}, 1 \mathrm{H}), 5.74(\mathrm{~d}, J=8.1 \mathrm{~Hz}, 1 \mathrm{H}), 3.76(\mathrm{~d}, J=10.4 \mathrm{~Hz}, 1 \mathrm{H})$, $3.63-3.58(\mathrm{~m}, 2 \mathrm{H}), 3.22(\mathrm{~s}, 1 \mathrm{H}), 1.87(\mathrm{dd}, J=10.7,8.7 \mathrm{~Hz}, 1 \mathrm{H})$, $1.69(\mathrm{dd}, J=10.8,6.6 \mathrm{~Hz}, 1 \mathrm{H}), 1.23$ (s, 3H), 1.17-0.89 (m, $4 \mathrm{H}), 0.82(\mathrm{~m}, 18 \mathrm{H}), 0.01(\mathrm{~m}, 12 \mathrm{H}) ;{ }^{13} \mathrm{C} \mathrm{NMR}\left(\mathrm{CDCl}_{3}, 75\right.$ $\mathrm{MHz}) \delta 162.9,150.5,141.6,102.4,85.6,71.3,62.2,40.0$, 31.2, 29.8, 25.4, 18.5, 14.7, 11.7, 9.3, -5.4; Anal. Calcd. for $\mathrm{C}_{25} \mathrm{H}_{46} \mathrm{~N}_{2} \mathrm{O}_{4} \mathrm{Si}_{2}: \mathrm{C}, 60.68 ; \mathrm{H}, 9.37 ; \mathrm{N}$, 5.66. Found: $\mathrm{C}, 60.75$; $\mathrm{H}, 9.41 ; \mathrm{N}, 5.70$.

(rel)-(4S,6S,7S)-1-[7-(t-Butyldimethylsilanyloxy)-6-( $t$ butyldimethylsilanyloxymethyl) 6-methylspiro[2.4]hept-4-yl] thymine (20): Thymine nucleoside analogue was prepared from mesylate $\mathbf{1 6}$ using a similar procedure as described for 17. Yield $21 \%$; mp $161-163{ }^{\circ} \mathrm{C}$; UV (MeOH) $\lambda_{\max } 267.5 \mathrm{~nm}$; ${ }^{1} \mathrm{H}$ NMR $\left(\mathrm{CDCl}_{3}, 300 \mathrm{MHz}\right) \delta 8.45(\mathrm{~s}, 1 \mathrm{H}), 6.98(\mathrm{~s}, 1 \mathrm{H})$, $3.76(\mathrm{~d}, J=10.4 \mathrm{~Hz}, 1 \mathrm{H}), 3.70-3.65(\mathrm{~m}, 2 \mathrm{H}), 3.25(\mathrm{~s}, 1 \mathrm{H})$, $1.96(\mathrm{~s}, 3 \mathrm{H}), 1.86(\mathrm{dd}, J=10.7,8.6 \mathrm{~Hz}, 1 \mathrm{H}), 1.71(\mathrm{dd}, J=$ $10.8,6.7 \mathrm{~Hz}, 1 \mathrm{H}), 1.31(\mathrm{~s}, 3 \mathrm{H}), 1.21-0.99(\mathrm{~m}, 4 \mathrm{H}), 0.82(\mathrm{~m}$, $18 \mathrm{H}), 0.01(\mathrm{~m}, 12 \mathrm{H}) ;{ }^{13} \mathrm{C} \mathrm{NMR}\left(\mathrm{CDCl}_{3}, 75 \mathrm{MHz}\right) \delta 164.8$, 163.2, 157.7, 99.6, 86.4, 70.6, 60.2, 39.6, 30.5, 28.3, 25.7, 18.8, 15.8, 12.9, 12.3, 9.2, -5.6; Anal. Calcd. for $\mathrm{C}_{26} \mathrm{H}_{48} \mathrm{~N}_{2} \mathrm{O}_{4} \mathrm{Si}_{2}$ : C, 61.37; H, 9.51; N, 5.51. Found: C, 61.42; H, 9.45; N, 5.49 .

(rel)-(4S,6S,7S)-9-[7-(Hydroxy)-6-(hydroxymethyl)-6methylspiro[2.4]hept-4-yl] adenine (21): To a solution of protected adenine analogue $20(240 \mathrm{mg}, 0.463 \mathrm{mmol})$ in cosolvent $\left(7.0 \mathrm{~mL}, \mathrm{THF} / \mathrm{CH}_{3} \mathrm{CN}=1: 1\right)$ was added $\mathrm{TBAF}$ $\left(1.39 \mathrm{~mL}, 1.0 \mathrm{M}\right.$ solution in THF) at $0{ }^{\circ} \mathrm{C}$. The mixture was stirred for $36 \mathrm{~h}$ at room temperature and then concentrated. The residue was purified by silica gel column chromatography $\left(\mathrm{MeOH} / \mathrm{CH}_{2} \mathrm{Cl}_{2}, 1: 4\right)$ to give $21(101 \mathrm{mg}, 76 \%)$ as a white solid. mp 236-239 ${ }^{\circ} \mathrm{C}$; UV $\left(\mathrm{H}_{2} \mathrm{O}\right) \lambda_{\max } 260.0 \mathrm{~nm} ;{ }^{1} \mathrm{H}$ NMR $\left(\mathrm{DMSO}-d_{6}, 300 \mathrm{MHz}\right) \delta 8.21(\mathrm{~s}, 1 \mathrm{H}), 7.85(\mathrm{~s}, 1 \mathrm{H}), 7.18(\mathrm{br}$ d, $2 \mathrm{H}, \mathrm{D}_{2} \mathrm{O}$ exchangeable), $4.97\left(\mathrm{~d}, J=4.8 \mathrm{~Hz}, 1 \mathrm{H}, \mathrm{D}_{2} \mathrm{O}\right.$ exchangeable), 4.85 (t, $J=4.8 \mathrm{~Hz}, 1 \mathrm{H}, \mathrm{D}_{2} \mathrm{O}$ exchangeable), 3.79 (dd, $J=8.8,6.8 \mathrm{~Hz}, 1 \mathrm{H}), 3.44$ (d, $J=10.0 \mathrm{~Hz}, 1 \mathrm{H}), 3.38$ $(\mathrm{d}, J=10.1 \mathrm{~Hz}, 1 \mathrm{H}), 3.19(\mathrm{~s}, 1 \mathrm{H}), 1.86(\mathrm{dd}, J=10.2,8.8 \mathrm{~Hz}$, 1H), 1.76 (dd, $J=10.2,6.8 \mathrm{~Hz}, 1 \mathrm{H}), 1.18$ (s, 3H), 1.12-0.90 $(\mathrm{m}, 4 \mathrm{H}) ;{ }^{13} \mathrm{C}$ NMR (DMSO- $\left.d_{6}, 75 \mathrm{MHz}\right) \delta 156.4,152.3$, 148.8, 140.2, 119.3, 85.4, 68.3, 56.9, 37.6, 28.4, 27.2, 15.4, 11.2, 8.8; Anal. Calcd. for $\mathrm{C}_{14} \mathrm{H}_{19} \mathrm{~N}_{5} \mathrm{O}_{2}$ : C, 58.12; $\mathrm{H}, 6.62 ; \mathrm{N}$, 24.21. Found: C, 58.08; H, 6.57; N, 24.19.

(rel)-(4S,6S,7S)-1-[7-(Hydroxy)-6-(hydroxymethyl)-6methylspiro[2.4]hept-4-yl] cytosine (22): Similar coupling conditions as described for adenine synthesis 21 were used for the preparation of cytosine analogue. Yield 85\%; mp 169-171 ${ }^{\circ} \mathrm{C}$; UV $\left(\mathrm{H}_{2} \mathrm{O}\right) \lambda_{\max } 271.0 \mathrm{~nm} ;{ }^{1} \mathrm{H}$ NMR (DMSO- $d_{6}$, $300 \mathrm{MHz}) \delta 7.87(\mathrm{~d}, J=6.1 \mathrm{~Hz}, 1 \mathrm{H}), 7.06\left(\mathrm{br} \mathrm{d}, 2 \mathrm{H}, \mathrm{D}_{2} \mathrm{O}\right.$ exchangeable), $6.12(\mathrm{~d}, J=6.0 \mathrm{~Hz}, 1 \mathrm{H}), 4.99(\mathrm{~d}, J=4.4 \mathrm{~Hz}, 1 \mathrm{H}$, $\mathrm{D}_{2} \mathrm{O}$ exchangeable), $4.78\left(\mathrm{t}, J=4.3 \mathrm{~Hz}, 1 \mathrm{H}, \mathrm{D}_{2} \mathrm{O}\right.$ exchangeable), 3.61 (d, $J=10.2 \mathrm{~Hz}, 1 \mathrm{H}), 3.52$ (d, $J=10.1 \mathrm{~Hz}, 1 \mathrm{H}), 3.42$ (d, $J$ $=10.0 \mathrm{~Hz}, 1 \mathrm{H}), 3.21(\mathrm{~s}, 1 \mathrm{H}), 1.66(\mathrm{dd}, J=10.6,8.7 \mathrm{~Hz}, 1 \mathrm{H})$, $1.52(\mathrm{dd}, J=10.6,6.8 \mathrm{~Hz}, 1 \mathrm{H}), 1.17(\mathrm{~s}, 3 \mathrm{H}), 1.11-0.87(\mathrm{~m}$, $4 \mathrm{H}) ;{ }^{13} \mathrm{C}$ NMR (DMSO- $\left.d_{6}, 75 \mathrm{MHz}\right) \delta 166.5,164.7,155.2$, 99.1, 83.6, 68.5, 55.5, 36.3, 30.2, 27.9, 14.5, 11.6, 9.0; Anal. Calcd. for $\mathrm{C}_{13} \mathrm{H}_{19} \mathrm{~N}_{3} \mathrm{O}_{3} \cdot 1.0 \mathrm{MeOH}$ : C, 56.54; H, 7.79; N, 14.13. Found: C, 56.49; H, 7.82; N, 14.11.

(rel)-(4S,6S,7S)-1-[7-(Hydroxy)-6-(hydroxymethyl)-6methylspiro[2.4]hept-4-yl] uracil (23): Uracil analogue 23 
was prepared under similar coupling conditions as described for adenine synthesis 21. Yield 79\%; mp 178-180 ${ }^{\circ} \mathrm{C}$; UV $\left(\mathrm{H}_{2} \mathrm{O}\right) \lambda_{\max } 263.5 \mathrm{~nm} ;{ }^{1} \mathrm{H}$ NMR (DMSO- $\left.d_{6}, 300 \mathrm{MHz}\right) \delta 7.68$ $(\mathrm{d}, J=8.0 \mathrm{~Hz}, 1 \mathrm{H}), 5.69$ (d, $J=8.0 \mathrm{~Hz}, 1 \mathrm{H}), 4.97$ (br s, $1 \mathrm{H}, \mathrm{D}_{2} \mathrm{O}$ exchangeable), $4.77\left(\mathrm{t}, J=4.5 \mathrm{~Hz}, 1 \mathrm{H}, \mathrm{D}_{2} \mathrm{O}\right.$ exchangeable), $3.64(\mathrm{~d}, J=10.4 \mathrm{~Hz}, 1 \mathrm{H}), 3.56$ (d, $J=10.4 \mathrm{~Hz}, 1 \mathrm{H}), 3.48$ (dd, $J=6.8,4.4 \mathrm{~Hz}, 1 \mathrm{H}), 3.20(\mathrm{~s}, 1 \mathrm{H}), 1.68(\mathrm{dd}, J=10.6,8.6 \mathrm{~Hz}$, $1 \mathrm{H}), 1.48(\mathrm{dd}, J=10.7,6.5 \mathrm{~Hz}, 1 \mathrm{H}), 1.32(\mathrm{~s}, 3 \mathrm{H}), 1.19-0.91$ $(\mathrm{m}, 4 \mathrm{H}) ;{ }^{13} \mathrm{C}$ NMR (DMSO- $\left.d_{6}, 75 \mathrm{MHz}\right) \delta 164.7,151.5$, 143.2, 101.3, 85.1, 67.8, 55.3, 35.8, 28.3, 27.3, 15.2, 12.2, 8.9; Anal. Calcd. for $\mathrm{C}_{13} \mathrm{H}_{18} \mathrm{~N}_{2} \mathrm{O}_{4}$ : C, 58.63; H, 6.81; N, 10.52. Found: C, 58.59; H, 6.78; N, 10.49.

(rel)-(4S,6S,7S)-1-[7-(Hydroxy)-6-(hydroxymethyl)-6methylspiro[2.4]hept-4-yl] thymine (24): Final thymine nucleoside analogue was obtained using similar coupling conditions as described for adenine synthesis 21 . Yield $82 \%$; mp 166-168 ${ }^{\circ} \mathrm{C}$; UV $\left(\mathrm{H}_{2} \mathrm{O}\right) \lambda_{\max } 267.5 \mathrm{~nm} ;{ }^{1} \mathrm{H}$ NMR (DMSO$\left.d_{6}, 300 \mathrm{MHz}\right) \delta 7.51(\mathrm{~s}, 1 \mathrm{H}), 5.01\left(\mathrm{~d}, J=4.4 \mathrm{~Hz}, 1 \mathrm{H}, \mathrm{D}_{2} \mathrm{O}\right.$ exchangeable), 4.81 (br s, $1 \mathrm{H}, \mathrm{D}_{2} \mathrm{O}$ exchangeable), 3.70 (d, $J$ $=10.7 \mathrm{~Hz}, 1 \mathrm{H}), 3.61(\mathrm{~d}, J=10.6 \mathrm{~Hz}, 1 \mathrm{H}), 3.51(\mathrm{br} \mathrm{s}, 1 \mathrm{H})$, $3.23(\mathrm{~s}, 1 \mathrm{H}), 1.92$ (s, 3H), $1.72(\mathrm{dd}, J=10.7,8.7 \mathrm{~Hz}, 1 \mathrm{H})$, 1.55 (dd, $J=10.8,6.7 \mathrm{~Hz}, 1 \mathrm{H}), 1.23$ (s, 3H), 1.15-0.89 (m, $4 \mathrm{H}) ;{ }^{13} \mathrm{C}$ NMR (DMSO- $\left.d_{6}, 75 \mathrm{MHz}\right) \delta 165.2,151.7,139.2$, 109.3, 86.4, 68.3, 54.5, 36.3, 28.8, 27.4, 16.2, 12.5, 11.3, 9.2; Anal. Calcd. for $\mathrm{C}_{14} \mathrm{H}_{20} \mathrm{~N}_{2} \mathrm{O}_{4} \cdot 0.5 \mathrm{MeOH}$ : C, 58.76; H, 7.48; N, 9.45. Found: C, 58.82; H, 7.51; N, 9.43.

Acknowledgments. This Study was supported by Technology Development Program for Agriculture and Forestry, Ministry of Agriculture and Forestry, Republic of Korea, 2010.

\section{References}

1. Szabo, E.; Lotz, G.; Paska, C.; Kiss, A.; Schaff, Z. Pathol. Oncol. Res. 2003, 9, 215.

2. Hughes, C. A.; Shafran, S. D. Ann. Pharmacother. 2006, 40, 479.

3. (a) Chiacchio, U.; Borrello, L.; Crispino, L.; Rescifina, A.; Merino, P.; Macchi, B.; Balestrieri, E.; Mastino, A.; Piperno, A.; Romeo, G. J. Med. Chem. 2009, 52, 4054. (b) Gunic, E.; Chow, S.; Rong, F.; Ramasamy, K.; Raney, A.; Li, D. Y.; Huang, J.; Hamatake, R. K.; Hong, Z.; Girardet, J. L. Bioorg. Med. Chem. Lett. 2007, 17, 2456. (c) Koch, U.; Narjes, F. Curr. Top. Med. Chem. 2007, 7, 1302 .

4. Kim, H. J.; Sharon, A.; Bal, C.; Wang, J.; Allu, M.; Huang, Z.; Murray, M. G.; Bassit, L.; Schinazi, R. F.; Korba, B.; Chu, C. K. J. Med. Chem. 2009, 52, 206.

5. Eldrup, A. B.; Allerson, C. R.; Bennett, C. F.; Bera, S.; Bhat, B.; Bhat, N.; Bosserman, M. R.; Brooks, J.; Burlein, C.; Carrol, S. S.; Cook, P. D.; Getty, K. L.; MacCross, M.; McMasters, D. R.; Olsen, D. B.; Prakash, T. P.; Prhavc, M. Song, Q. L.; Tomassini, J. E.; Xia, J. J. Med. Chem. 2004, 47, 2283.
6. Clark, J. L.; Hollecker, L.; Mason, J. C.; Stuyver, L. J.; Tharnish, P. M.; Lostia, S.; McBrayer, T. R.; Schinazi, R. F.; Watanabe, K. A.; Otto, M. J.; Furman, P. A.; Stec, W. J.; Patterson, S. E.; Pankiewicz, K. W. J. Med. Chem. 2005, 48, 5504.

7. Jonckers, T. H.; Lin, T. I.; Buyck, C.; Lachau-Durand, S.; Vandyck, K.; Van Hoof, S.; Vandekerckhove, L. A.; Hu, L.; Berke, J. M.; Vijgen, L.; Dillen, L. L.; Cummings, M. D.; de Kock, H.; Nilsson, M.; Sund, C.; Rydegård, C.; Samuelsson, B.; Rosenquist, A.; Fanning, G.; Van Emelen, K.; Simmen, K.; Raboisson, P. J. Med. Chem. 2010, 53, 8150.

8. Boojamra, C. G.; Parrish, J. P.; Sperandio, D.; Gao, Y.; Petrakovsky, O. V.; Lee, S. K.; Markevich, D. Y.; Vela, J. E.; Laflamme, G.; Chen, J. M.; Ray, A. S.; Barron, A. C.; Sparacino, M. L.; Desai, M. C.; Kim, C. U.; Cihlar, T.; Mackman, R. L. Bioorg. Med. Chem. 2009, 17, 1739.

9. (a) Smith, D. B.; Kalayanov, G.; Sund, C.; Winqvist, A.; Maltseva, T.; Leveque, V. J.; Rajyaguru, S.; Pogam, S. L.; Najera, I.; Benkestock, K.; Zhou, X. X.; Kaiser, A. C.; Maag, H.; Cammack, N.; Martin, J. A.; Swallow, S.; Johansson, N. G.; Klumpp, K.; Smith, M. J. Med. Chem. 2009, 52, 219. (b) Rondla, R.; Coats, S. J.; McBrayer, T. R.; Grier, J.; Johns, M.; Tharnish, P. M.; Whitaker, T.; Zhou, L.; Schinazi, R. F. Antiviral Chem. Chemother. 2009, 20, 99. (c) Gosselin, G.; Griffe, L.; Meillon, J.-C.; Storer, R. Tetrahedron 2006, 62, 906. (d) Meillon, J. C.; Griffe, L.; Storer, R.; Gosselin, G. Nucleosides, Nucleotides \& Nucleic Acids 2005, 24, 695.

10. (a) Crimmins, M. T. Tetrahedron 1998, 54, 9229. (b) Jeong, L. S.; Lee, J. A. Antiviral Chem. Chemother. 2004, 15, 235. (c) Ariona, O.; Gómez, A. M.; López, J. C.; Plumet, J. Chemical Reviews 2007, 107, 1919.

11. Kim, A.; Hong, J. H. Nucleosides, Nucleotides \& Nucleic Acids 2005, 24, 63 .

12. (a) Deiters, A.; Martin, S. F. Chem. Rev. 2004, 104, 2199. (b) Romeo, G.; Chiacchio, U.; Corsaro, A.; Merino, P. Chem. Rev. 2010, 110, 3337. (c) Jeong, L. S.; Lee, J. A. Antiviral Chem. Chemother. 2004, 15, 235. (d) Amblard, F.; Nolan, S. P.; Agrofoglio, L. A. Tetrahedron 2005, 61, 7067. (e) McReynolds, M. D.; Dougherty, J. M.; Hanson, P. R. Chem. Rev. 2004, 104, 2230.

13. Ruder, S. M.; Ronald, R. C. Tetrahedron Lett. 1984, 25, 5501.

14. (a) Yin, X. Q.; Li, W. K.; Yang, M.; Schneller, S. W. Bioorg. Med. Chem. 2009, 17, 3126. (b) Sisu, E.; Sollogoub, M.; Mallet, J. M.; Sinay, P. Tetrahedron 2002, 58, 10189. (c) Takaku, H.; Kamaike, K.; Tsuchiya, H. J. Org. Chem. 1984, 49, 51.

15. (a) Horita, K.; Yoshioka, T.; Tanaka, T.; Oikawa, Y.; Yonemitsu, O. Tetrahedron 1986, 42, 3021. (b) Oikawa, Y.; Tanaka, T.; Horita, K.; Yonemitsu, O. Tetrahedron Lett. 1984, 25, 5397.

16. (a) Pathak, T.; Bazin, H. Chattopadhyaya, J. Tetrahedron 1986, 42, 5427. (b) Revankar, G. R.; Gupta, P. K.; Adams, A. D.; Dalley, N. K.; McKernan, P. A.; Cook, P. D.; Canonico, P. G.; Robins, R. K. J. Med Chem. 1984, 27, 1389.

17. Panzica, R. P.; Rousseau, R. J.; Robins, R. K.; Townsend, L. B. J. Am. Chem. Soc. 1972, 94, 4708.

18. Bonnal, C.; Chavis, C.; Lucas, M. J. Chem. Soc. Perkin Trans. 1 1994, 1401.

19. Liu, L. J.; Hong, J. H. Nucleosides, Nucleotides \& Nucleic Acids 2009, $28,1007$. 